\title{
NEW INSTRUMENT FOR ESTABLISHING A FILTERING CHANNEL IN CHRONIC GLAUCOMA*
}

\author{
BY
}

\author{
M. H. M. EMARAH \\ Cairo
}

CASES of chronic simple (open-angle) glaucoma not responding to medical therapy usually require a drainage operation. Various instruments are used to establish a filtering channel between the angle of the anterior chamber and the subconjunctival space. Each of these has its own merits and drawbacks. In this paper a new form of scleral punch is described which has been designed to eliminate the difficulties encountered with some of the current instruments.

\section{Description of Instrument $\uparrow$}

The instrument is shown assembled in Fig. 1. It consists of a narrow tubular barrel (Fig. 2A) into which is fitted a spring-loaded plunger (Fig. 2B) terminating in a cutting edge. The instrument has a handle (Fig. 2C) which serves as convenient finger support when the thumb depresses the spring-loaded plunger.

The lower end of the barrel is prolonged by a short extension which is hook-shaped. The lower lip of the barrel (Fig. 2A, d) is of minimal thickness and can be supplied in two

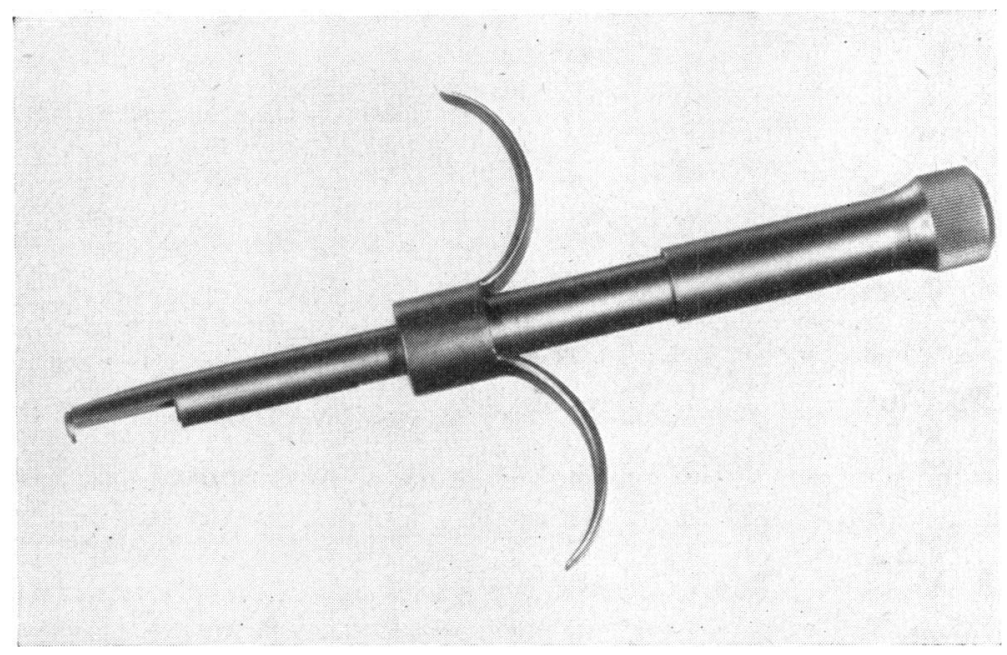

FIG. 1.-Side view of the instrument showing barrel, plunger, and handle assembled.

\footnotetext{
* Received for publication October 9, 1964.
}

$\dagger$ The instrument is manufactured by and may be obtained from Keeler Ltd., Wigmore Street, London, W.1. 


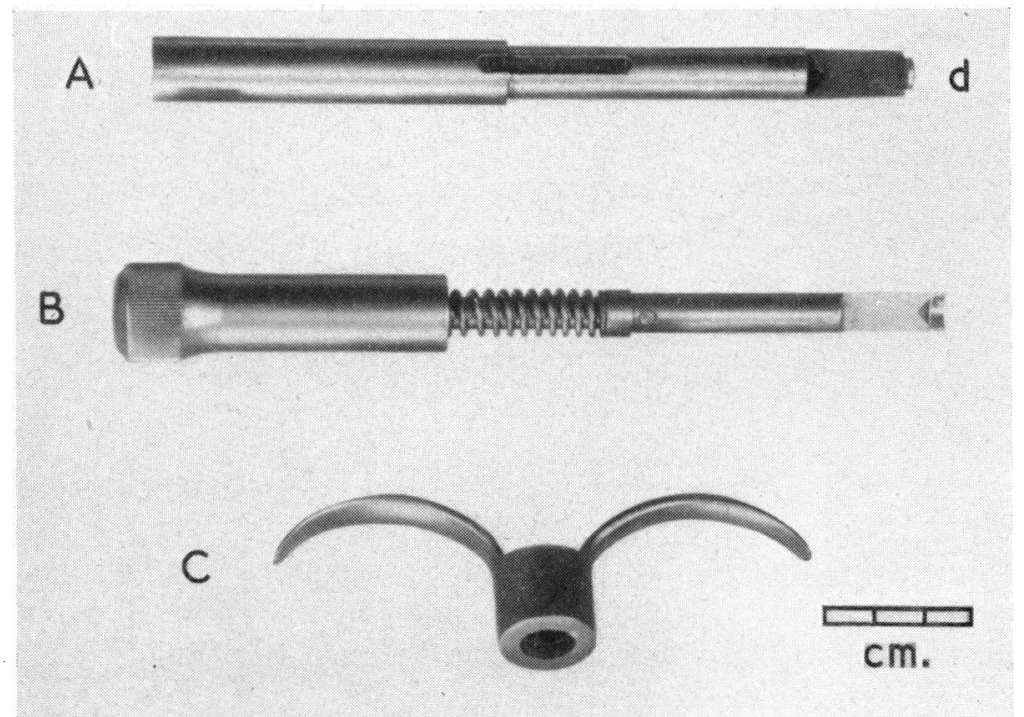

FIG. 2.-Component parts of the instrument before assembly. A, Tubular barrel. B, Spring-loaded plunger. C, Handle which also serves as finger support.

sizes, $1.5 \mathrm{~mm} . \times 1.5 \mathrm{~mm}$. or $2.0 \mathrm{~mm} . \times 1.5 \mathrm{~mm}$. The plunger, on the other hand, terminates in a sharp cutting edge which is accurately ground to engage against the rim of the lower lip of the barrel. The plunger is maintained in accurate alignment with the lower end of the punch by providing flattened parts on the shaft of the former corresponding to those within the tubular barrel. This prevents relative axial rotation of the two components. The downward motion of the plunger is limited by a stop to prevent the cutting edge from passing beyond the lower lip of the punch, thus avoiding damage to the interior of the eye through too deep a penetration.

\section{Proposed Technique of Operation*}

(1) The pre-operative preparation and anaesthesia are the same as for any other drainage operation.

(2) The superior rectus tendon is grasped and a No. 1 white silk suture is passed beneath it. This is retracted with a Spencer-Wells forceps so as to fix the eye in the required depressed position.

(3) An incision concentric with the limbus and 7-8 $\mathrm{mm}$. above the cornea is made through the conjunctiva and Tenon's capsule. The conjunctival flap is dissected until the edge of the corneo-scleral junction is clearly defined (Fig. 3, I). Bleeding points are checked by a heated probe.

(4) An incision concentric with the limbus about 6-7 mm. long is made through the corneo-scleral junction into the filtration angle. This incision should be made at right angles to the corneal surface (Fig. 3, Ia).

(5) The lower lip of the punch is inserted as required under the posterior or anterior edge of the wound (Fig. 3, II a and b). The plunger, held nearly vertically, is depressed by the thumb, pressure being maintained until the instrument is removed from the eye. This results in a sclerectomy of variable size, according to the amount of sclera which has been held in the punch, the maximum surface area being approximately $4.71 \mathrm{~mm}$. (Fig. 3, III).

\footnotetext{
* This instrument has been tried with success on eyes prior to enucleation. Results of its use on patients suffering from glaucoma will be published at a later date.
} 


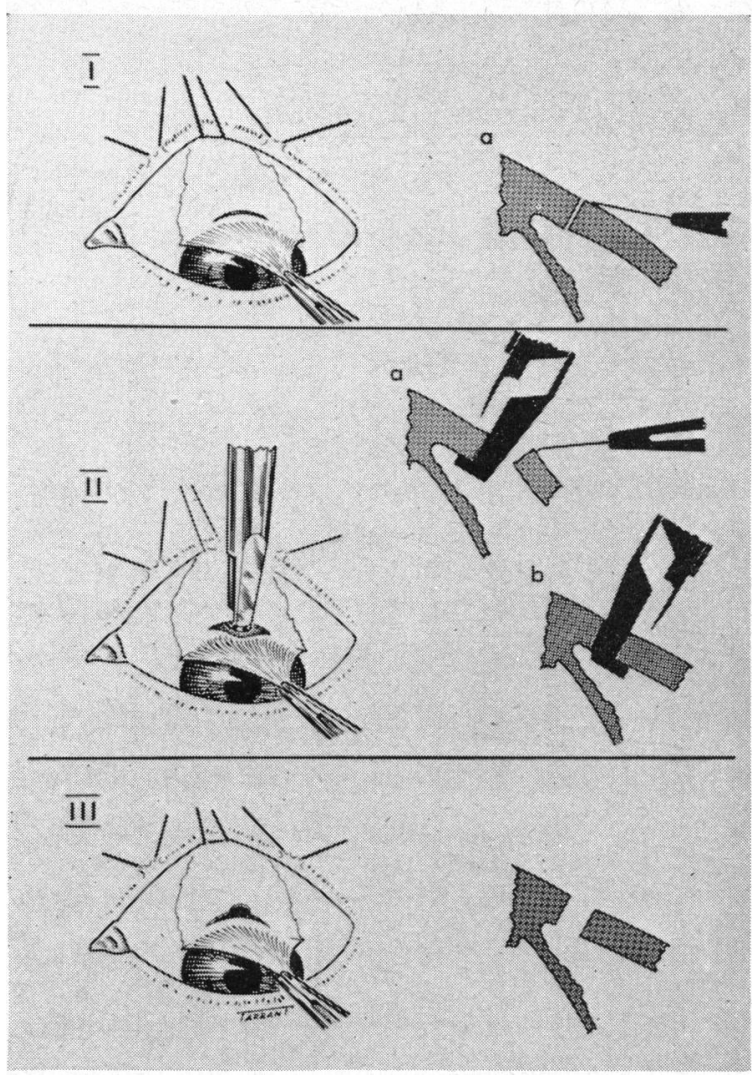

FIG. 3.-Stages in the operation. I, Dissection of conjunctival flap and incision. II, Punch inserted under edge of wound, a, under posterior, b, under anterior, flap. III, Sclerectomy resulting from use of punch.

(7) No pressure is exerted on the eyeball when using the punch.

(8) There is no danger of injuring the lens or damaging the interior of the eye through accidental deep penetration.

I wish to express my sincere thanks and gratitude to all who have helped me in this work. In particular I am grateful to Prof. David Slome at the Royal College of Surgeons, who helped me in the experimental trial; to Mr. C. A. G. Cook at Guy's, Mr. J. S. Groves at the Coventry and Warwickshire Hospital, and to Mr. S. J. H. Miller at Moorfields, for their encouragement and practical comments. I thank Mr. John Hook, London, who manufactured the prototype for me, and Mr. I. D. C. Pain of Keeler, for his co-operation. I would also like to thank Mr. C. H. Redman for taking the photographs (Figs 1 and 2 ) and $\mathrm{Mr}$. T. Tarrant for making the drawing of Fig. 3.
(6) A small basal iridectomy is then performed.

(7) The conjunctival wound is closed.

(8) The post-operative management is the same as for any other drainage operation.

\section{Advantages of the Punch}

(1) The design is simple.

(2) The instrument is easy to steri-

(3) The punch cuts only the desired area of sclera overlying the angle, which is all that is required to produce drainage of the aqueous into the subconjunctival space. The risk of button-holing the conjunctiva becomes practically non-existent, as corneal splitting is not required when using the punch.

(4) The operator, using the instrument with one hand, hooks the scleral flap overlying the angle with the lower lip of the punch, and cuts it by depressing the plunger.

(5) The excised scleral tissue is trapped into the punch and there is no chance of it being lost in the anterior chamber.

(6) The same punch can be used to cut either the anterior or posterior edge of the limbal wound as desired. 